\title{
Geografia Física e questões ambientais: um balanço em periódicos científicos da região Nordeste (2006-2015)
}

\author{
Physical Geography and environmental issues: a balance in scientific periodicals of \\ Northeast region (2006-2015)
}

\author{
Silva $^{1}$, F. J. L. T; Aquino $^{2}$, C. M. S.
}

lennonufpi@hotmail.com

\begin{abstract}
Resumo
As questões ambientais constituem importante tema de pesquisa para os estudos de Geografia Física. Nesse sentido, o artigo teve por objetivo realizar um balanço dos temas que envolvem a problemática ambiental no âmbito dos periódicos científicos editados pelos programas de pós-graduação em Geografia de universidades públicas federais e estaduais da região Nordeste, no período de 2006 a 2015. Os temas mais trabalhados nos periódicos analisados foram: impactos ambientais urbanos, análise ambiental em bacias hidrográficas, ensaios teóricos, uso/ocupação e cobertura da terra, degradação ambiental/desertificação, geoconservação/geodiversidade, educação ambiental e legislação ambiental. Os estudos em escala local se destacaram, assim como a aplicação da abordagem sistêmica.
\end{abstract}

Palavras-chave: Questões ambientais. Geografia Física. Periódicos científicos.

\begin{abstract}
Environmental issues are an important subject of research for studies of Physical Geography. In this sense, the article aimed accomplish a balance of themes involving environmental issues in the context of scientific journals edited by post-graduate programs in Geography of public federal and state universities in the Northeast region, in the 2006 to 2015 period. The most worked themes in the journals analyzed were: urban environmental impacts, environmental analysis in watersheds, theoretical essays, use/occupation and land cover, environmental degradation/desertification, geoconservation/geodiversity, environmental education and environmental legislation. The studies on local scale stood out, as well as the application of systemic approach.
\end{abstract}

Keywords: Environmental issues. Physical Geography. Scientific periodicals

\section{INTRODUÇÃO}

A crescente preocupação com a chamada "questão ambiental" refletida na incessante busca por abordagens que possibilitem a análise integrada das inter-relações entre sociedade e natureza tem propiciado a contínua revisão dos métodos, abordagens e importância aplicada da ciência geográfica. Nessa atmosfera de reavaliação crítica, são significativas as contribuições que procuram discutir o equacionamento da problemática ambiental pelo viés geográfico, tais como Mendonça (1989; 1993; 2002), Monteiro (1999), Suertegaray e Nunes (2001) e Suertegaray (2002).

Evidência ilustrativa da relevância que a dimensão ambiental possui no cenário contemporâneo das pesquisas geográficas pode ser encontrada nas publicações em periódicos científicos. Periódicos científicos representam espaços para a divulgação de estudos aplicados ao 
largo temário da investigação geográfica, sendo que a cada novo número publicado são postos à vista as mais recentes preocupações temáticas.

Os periódicos científicos, devido ao fato de possuírem amplo alcance, constituem-se em canais abertos de acesso à produção científica de ponta, podendo eventualmente determinar novas rotas de pesquisa (DOYLE; JULIAN, 2005). Acredita-se, portanto, que a análise dos artigos publicados em periódicos científicos regionais devotados aos estudos geográficos constitui uma notável ferramenta para se traçar o panorama geral da produção deste importante ramo do conhecimento no contexto dos debates sobre as questões ambientais.

Nessa perspectiva, objetivou-se com a presente pesquisa realizar um balanço dos temas e tendências que envolvem a problemática ambiental no âmbito dos periódicos científicos editados pelos programas de pós-graduação em Geografia de universidades públicas federais e estaduais da região Nordeste.

\section{MATERIAIS E PROCEDIMENTOS METODOLÓGICOS}

Os critérios de seleção dos periódicos científicos regionais foram: (i) vínculo institucional a programas de pós-graduação em Geografia de Universidades públicas federais e/ou estaduais e (ii) abertura temática aos estudos de Geografia Física (QUADRO 01)

\begin{tabular}{|c|c|c|}
\hline Periódicos & Anos levantados & Vínculo institucional \\
\hline $\begin{array}{c}\text { Revista da Casa da } \\
\text { Geografia de Sobral }\end{array}$ & $2006-2015$ & $\begin{array}{c}\text { Programa de pós-graduação em Geografia da } \\
\text { Universidade Estadual Vale do Acaraú }\end{array}$ \\
\hline Revista de Geografia & $2006-2015$ & $\begin{array}{c}\text { Programa de pós-graduação em Geografia da } \\
\text { Universidade Federal de Pernambuco }\end{array}$ \\
\hline Revista Equador & $2012-2015$ & $\begin{array}{c}\text { Programa de pós-graduação em Geografia da } \\
\text { Universidade Federal do Piauí }\end{array}$ \\
\hline Revista Geonordeste & $2006-2015$ & $\begin{array}{c}\text { Programa de pós-graduação em Geografia da } \\
\text { Universidade Federal de Sergipe }\end{array}$ \\
\hline Revista Geosaberes & $2010-2015$ & $\begin{array}{c}\text { Programa de pós-graduação em Geografia da } \\
\text { Universidade Federal do Ceará }\end{array}$ \\
\hline Revista Geotextos & $2006-2015$ & $\begin{array}{c}\text { Programa de pós-graduação em Geografia da } \\
\text { Universidade Federal da Bahia }\end{array}$ \\
\hline Revista Geouece & $2012-2015$ & $\begin{array}{c}\text { Programa de pós-graduação em Geografia da } \\
\text { Universidade Estadual do Ceará }\end{array}$ \\
\hline Revista Mercator & $2006-2015$ & $\begin{array}{c}\text { Programa de pós-graduação em Geografia da } \\
\text { Universidade Federal do Ceará }\end{array}$ \\
\hline Revista Okara & $2007-2015$ & $\begin{array}{c}\text { Programa de pós-graduação em Geografia da } \\
\text { Universidade Federal da Paraíba }\end{array}$ \\
\hline Revista Sociedade e \\
Território
\end{tabular}

Quadro 01. Periódicos considerados para o levantamento dos artigos. Fonte: Organização dos autores (2016). 
Os periódicos em epígrafe foram preliminarmente analisados, na justa tentativa de assegurar a consistência temática dos mesmos com a problemática, objetivos e fundamentação teórica configuradores desta pesquisa. Foram consideradas apenas as edições eletrônicas dos periódicos selecionados. Não foram considerados números/edições especiais referentes a eventos científicos.

Em relação aos procedimentos de análise, a pesquisa se fundamentou no método bibliográfico, desenvolvido a partir de material já elaborado, constituído de livros, dissertações, teses e artigos.

\section{A QUESTÃO AMBIENTAL E OS ESTUDOS GEOGRÁFICOS}

Até a década de 1950, a Geografia Física caracterizou-se por estudos fragmentados dos aspectos do quadro natural. Com a crescente difusão das metas ligadas com a questão ambiental, a Geografia Física se viu aplacada pelo novo contexto das pesquisas, buscando novas referências teórico-metodológicas de análise (MENDONÇA, 1989).

Monteiro (1999) lembra que, a partir da eclosão da crise ambiental, sobretudo a partir dos anos de 1970, os geógrafos físicos redirecionaram os seus estudos à compreensão das questões ambientais e passaram a buscar respaldo em abordagens que melhor evidenciassem a relação Sociedade-Natureza em bases integrativas, destacando-se a abordagem geossistêmica.

Cita-se que a Geografia Física produzida nas décadas de 1980 e 1990 poderia ser chamada de "ambientalista", em vista do engajamento dos geógrafos em produzir trabalhos sobre a problemática do meio ambiente, refletindo-se em um volume crescente de publicações científicas voltadas para as questões ambientais (SOUZA; MARIANO, 2008).

Contemporaneamente, a questão ambiental configura-se como um dos temas constitutivos do escopo investigativo da ciência geográfica, exigindo da Geografia Física a constante revisão das suas concepções, incentivando seus praticantes a elaborarem novas propostas teóricas e metodológicas (MENDONÇA, 2010).

Os estudos que buscam refletir sobre a produção e tendências das pesquisas em Geografia Física em periódicos científicos apontam para o crescente interesse dos pesquisadores em analisar as perspectivas e desafios da ciência geográfica frente às questões ambientais.

Gregório (2007), ao realizar levantamento dos artigos publicados na Revista Brasileira de Geografia entre 1939 e 2005, verificou que na década de 1990 predominaram os trabalhos de cunho ambiental, com destaque para as pesquisas sobre impactos ambientais, diagnósticos ambientais e planejamento ambiental. 
Vitte (2008), ponderando sobre a produção geográfica no período de 1928 a 2006, assevera que a apropriação das questões ambientais pela Geografia Física mostra-se largamente registrada em periódicos científicos de impacto nacional, dentre eles: Revista GEOUSP, Revista Geografia (UNESP) e Boletim Goiano de Geografia.

Oliveira e Salgado (2013) analisaram os artigos publicados na Revista Brasileira de Geomorfologia, considerando o recorte temporal de 2006 a 2010, e destacam que, em meio aos temas clássicos e mais estudados pela Geomorfologia nacional, tais como processos de vertentes e geomorfologia fluvial, foram significativos os estudos sobre análise ambiental.

Ao se considerar que o propósito dos periódicos científicos de Geografia é divulgar pesquisas que tratam do objeto de estudo dessa ciência sob os mais diversos horizontes temáticos, infere-se que analisar como as questões ambientais têm sido discutidas nos periódicos regionais constitui contribuição de suma importância.

\section{RESULTADOS E DISCUSSÃO}

Em termos absolutos, foram produzidos 1.527 artigos, publicados em 10 periódicos regionais, entre 2006 e 2015. Desta cifra, foram contabilizados 235 artigos (15,3\%) com enfoque em questões ambientais, trabalhadas a partir de recortes temáticos múltiplos (GRÁFICO 01).

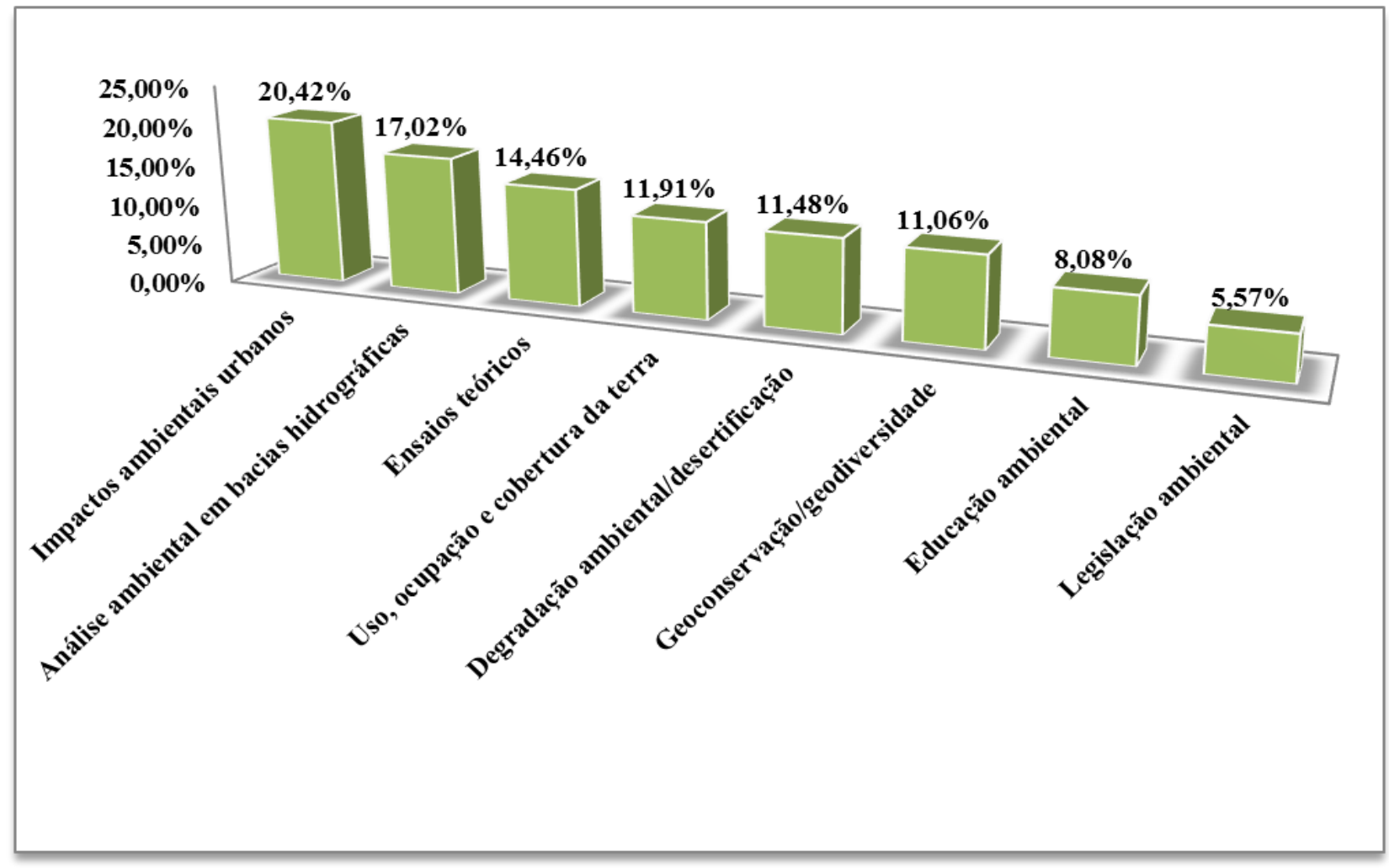

Gráfico 01. Recortes temáticos dos artigos com enfoque ambiental Elaboração dos autores (2016). 
Destaca-se que nem todos os estudos em Geografia Física têm por foco analisar a dinâmica relacional entre a sociedade e a natureza (MENDONÇA, 2002; SUERTEGARAY, 2002). Nesse sentido, sublinha-se que ainda são rotineiros os estudos de inventário e descrição dos condicionantes físicos de forma setorizada, tais como geomorfologia, associações de solos, cobertura vegetal, sistemas fluviais, dentre outros. São estudos que se limitam a obter dados geoambientais, cujos objetivos não comportam problematizar os reveses da interação bidirecional homem-meio, mas que nem por isso perdem espaço no âmbito das publicações científicas, em virtude da sua importância enquanto conhecimento básico.

Assim sendo, o percentual relativamente baixo de 15,3\% de estudos com preocupação ambiental deve ser analisado com cautela, haja vista que a questão ambiental seja apenas uma das múltiplas dimensões da realidade para as quais a lente do conhecimento geográfico pode ser apontada. Portanto, não procede concluir que a Geografia Física tem pouca importância no contexto dos periódicos regionais, naquilo que se refere aos estudos ambientais.

No quadro dos estudos com foco ambiental, notabilizaram-se as análises sobre impactos ambientais urbanos, análise ambiental em bacias hidrográficas, ensaios teóricos, uso/ocupação e cobertura da terra, degradação ambiental/desertificação, geoconservação/geodiversidade, educação ambiental e legislação ambiental. Em seu conjunto, a despeito das especificidades conceituais, as pesquisas buscam oferecer subsídios para a análise das questões ambientais, a partir de abordagens pautadas no nexo conceitual Sociedade-Natureza.

Neste viés de reflexão, parte das pesquisas focaliza a avaliação dos impactos já evidenciados (degradação/desertificação; impactos ambientais urbanos), procurando oferecer mecanismos para a sua reversão ou minimização; outras análises pautam-se em elaborar parâmetros para a manutenção do equilíbrio dos ambientes naturais perante os cenários tendenciais de exploração socioeconômica (geoconservação; uso/ocupação e cobertura da terra).

Particularmente nos estudos sobre uso/ocupação e cobertura da terra, observam-se as recorrentes propostas de levantamento e análise das capacidades, potencialidades e limitações dos sistemas ambientais frente às atividades humanas. Assim, o estudo setorizado dos componentes geoambientais (geologia, relevo, associações de solos, cobertura vegetal, recursos hídricos) é concebido como ponto de partida imprescindível para, dentre outras aplicações, as propostas de zoneamento ambiental.

Frisa-se que o interesse dos geógrafos pelos estudos ambientais acabou por reacender e revigorar os debates de cunho epistemológico, refletindo-se no significativo percentual de estudos 
teóricos. Neste ponto, são notórios os ensaios sobre as possibilidades e limites de aplicação da Geografia Física aos estudos ambientais, em que são discutidas a pertinência e validade dos seus métodos e abordagens.

Sob essa ótica, são evidentes as redefinições teórico-metodológicas, pautadas em pressupostos sistêmicos, em que a compreensão do conjunto dos fenômenos físicos face aos contextos econômico e social em bases epistemológicas integrativas emerge como desafio e preocupação norteadores. Em linhas gerais, destacaram-se as reflexões sobre a dicotomia Geografia Física versus Geografia Humana e análise sistêmica aplicada ao estudo integrado da paisagem.

Densas ponderações conceituais foram rastreadas nos artigos dedicados aos temas degradação ambiental e desertificação. Verifica-se que o tema desertificação ainda desperta controvérsias quanto às modalidades de ocorrência e políticas de combate. Por este ponto de vista, críticas e questões agudas são postas à comunidade geográfica. Citam-se, por exemplo, as considerações sobre a validação das escalas de abordagem. Outro tópico repousa sobre a consistência das metodologias já sistematizadas, as quais se apresentam sustentadas em diferentes parâmetros e critérios, ainda sem aceitação consensual.

Outras análises teóricas gravitaram em torno da inserção de abordagens humanísticas nos estudos ambientais. Menciona-se, por exemplo, a introdução de pressupostos fenomenológicos aos estudos socioambientais urbanos, em que o conceito de percepção ambiental emerge como tendência.

Cumpre mencionar o predomínio das pesquisas de âmbito local, destacando-se os estudos em escala municipal. Esta constatação encontra respaldo nas reflexões de Suertegaray e Nunes (2001) e Mendonça (2004; 2010). Para os autores retromencionados, esta tendência está, de fato, inerentemente associada aos estudos ambientais, visto que as análises locais buscam apontar soluções imediatas aos problemas vislumbrados.

Nessa mesma concepção, destacam-se os estudos sobre impactos ambientais urbanos. Ambiente construído e modificado em diversas escalas, as cidades configuram processos que se evidenciam de forma mais expressiva pontualmente, na escala do local (MENDONÇA, 2010). É no espaço urbano onde o quadro natural encontra-se mais fortemente alterado pela ação humana.

Salienta-se, ainda, que é na cidade onde as relações sociais são marcadas por fortes desigualdades socioeconômicas, evidenciadas na apropriação desigual do espaço. Análises específicas sobre poluição do ar e dos rios, assoreamento, conforto térmico, enchentes, inundações, deslizamento de encostas, disposição de resíduos sólidos, dentre outros, sobressaíram-se no eixo dos impactos ambientais urbanos. 
O tratamento dos problemas ambientais emanados da descompassada relação SociedadeNatureza em âmbito municipal/local também dá a tônica às análises ambientais em bacias hidrográficas, mormente naqueles sistemas fluviais situados próximos aos perímetros mais densamente urbanizados.

É oportuno destacar que as tendências associadas aos estudos ambientais se apresentam também como aporte técnico, com destaque para o uso em larga escala dos Sistemas de Informações Geográficas (SIGs) e das técnicas de Geoprocessamento e Sensoriamento Remoto.

Nessa conjuntura, Aquino e Valladares (2013) corroboram que o novo aparato geotecnológico representa um irrefutável avanço para a Geografia, na sua ânsia de espacializar e explicar os fenômenos em seus padrões e variabilidades têmporo-espaciais, viabilizando a sua aplicação às metas de planejamento ambiental e ordenamento territorial.

Portando, é natural que a aplicação dessas novas ferramentas figure como preocupação recorrente nos estudos geográficos. Não obstante, o uso substantivo dos SIGs reclama cautela teórico-metodológica - atitude imprescindível para se esclarecer o contexto no qual se colocam as problematizações. Assim sendo, não basta ao geógrafo localizar, delimitar e mapear com precisão; é necessário interpretar e fazer compreender as mudanças impostas ao espaço geográfico.

Nesse viés de análise e reflexão, admite-se que o aperfeiçoamento das técnicas de análise espacial pode contribuir de forma decisiva para tornar cada vez mais inteligível a fenomenologia ambiental, possibilitando o alargamento e recalibragem das formulações teóricas que procuram explicar a cambiante relação sociedade-natureza nos moldes históricos contemporâneos.

Em resumo, o levantamento dos artigos publicados em periódicos regionais permite concluir que o tratamento das questões ambientais tem exigido da Geografia Física novos expedientes conceituais, teóricos e metodológicos, de forma a proporcionar horizontes interpretativos exitosos para os estudos ambientais.

\section{CONSIDERAÇÕES FINAIS}

A crise ambiental que aplaca os princípios mais fundamentais da ciência geográfica é a mesma que oferece as condições para a sua superação. Nesse contexto, a análise geográfica é amplamente aplicável na avaliação e predição dos impactos ambientais.

Os pesquisadores que trabalham com Geografia Física têm apresentado resultados significativos em relação ao equacionamento das questões ambientais, somando forças em análises empíricas e teórico-metodológicas. Ao delinearem o posicionamento da Geografia Física face ao 
atual quadro das tendências temáticas, os geógrafos físicos têm procurado respaldo em abordagens integrativas e em técnicas emergentes, em que se destacam as ferramentas geotecnológicas.

Ao analisar as questões ambientais a partir do cabedal teórico-conceitual e técnico da Geografia Física, os pesquisadores contemplam a organização do espaço como objeto de estudo, donde a relação Sociedade-Natureza emerge como nexo conceitual norteador.

Dentro do objetivo delineado neste artigo, vislumbrou-se que a incorporação do discurso ambiental pelos estudos de Geografia Física está muito bem ilustrada nos periódicos científicos regionais, onde um significativo volume de publicações conexas ao temário ambiental aponta o novo ideário dos estudiosos dos sistemas ambientais: apresentar propostas e sugestões cientificamente embasadas e que possam a vir ajudar na preservação do meio ambiente.

Ainda no que se refere ao balanço dos artigos publicados em periódicos regionais, constatou-se que muitos são os pontos de partida para o estudo da relação Sociedade-Natureza, tais como impactos ambientais urbanos; análise de bacias hidrográficas; uso e cobertura da terra; educação ambiental, geoconservação; geodiversidade; degradação ambiental e desertificação.

Analisados em bloco, os estudos em tela procuram demonstrar que, em função da sua multidimensionalidade e expressividade espacial subjacente, a dilemática ambiental encontra na Geografia o cabedal técnico, conceitual e teórico-metodológico mais acurado e abrangente. Enquanto saber estratégico, o conhecimento geográfico tem um importante papel a desempenhar na construção de uma nova coerência entre a sociedade e a natureza.

Assim sendo, na perspectiva de assegurar à Geografia Física um lugar de destaque no desbravamento da matéria ambiental, urge que se prospectem resultados aplicados progressivamente mais amplos, articulados e consistentes. Para tanto, há que se continuar desenvolvendo os alicerces teóricos da ciência geográfica, com vistas a ajustar ao seu núcleo investigativo aqueles fenômenos ainda mal configurados no cronograma das pesquisas e no quadro das interrogações.

\section{REFERÊNCIAS}

AQUINO, C. M. S. VALLADARES, G. S. Geografia, geotecnologias e planejamento ambiental. Geografia, Londrina, v. 22, n.1, p. 117-138, jan/abr, 2013.

DOYLE, M. N.; JULIAN, J. P. The most cited works in Geomorphology. Geomorphology, 2005, n. 72 , p. $238-249$.

GREGÓRIO, A. C. Os caminhos da Geografia Física no Brasil a partir da análise da Revista Brasileira de Geografia (1939 a 2005). 37 f. Monografia. Universidade Federal de Viçosa, 2007. 
KÖCHE, J. C. Fundamentos de metodologia científica: teoria da ciência e iniciação à pesquisa. 30. ed. Petrópolis, Rio de Janeiro: Vozes, 2012.

MENDONÇA, F. Geografia física: ciência humana? São Paulo: Contexto, 1989.

. Geografia e meio ambiente. São Paulo: Contexto, 1993.

Geografia socioambiental. In: MENDONÇA, F.; KOZEL, S. (Org.). Elementos de epistemologia da Geografia contemporânea. Curitiba. Editora da UFPR, 2002.

Riscos, vulnerabilidade e abordagem socioambiental urbana: uma reflexão a partir da RMC e de Curitiba. Desenvolvimento e Meio Ambiente, n. 10, p. 139-148, jul./dez., 2004.

Riscos e vulnerabilidades socioambientais urbanos: a contingência climática. Revista Mercator, v. 9 (número especial, 1), p. 153-163, dez., 2010.

MONTEIRO, C. A. F. A abordagem ambiental na geografia - possibilidades na pesquisa e limitações do geógrafo ao monitoramento. Revista Rae'ga, Curitiba, v. 3, p. 9-18, 1999.

OLIVEIRA, C. K. R.; SALGADO, A. A. R. Geomorfologia brasileira: panorama geral da produção nacional de alto impacto no quinquênio entre 2006-2010. Revista Brasileira de Geomorfologia, v. 14, n. 1, p. 117-123, 2013.

SOUZA, M. B.; MARIANO, Z. F. Geografia Física e a questão ambiental no Brasil. Revista GEOUSP, n. 23, p. 77-98, 2008.

SUERTEGARAY, D. M. A.; NUNES, J. O. R. A natureza da Geografia Física na Geografia. São Paulo: Revista Terra Livre, n. 17, p. 11-24, 2001.

Geografia física (?) Geografia ambiental (?) ou Geografia e ambiente (?). In: MENDONÇA, F.; KOZEL, S. (Org.). Elementos de epistemologia da Geografia contemporânea. Curitiba. Editora da UFPR, 2002.

VITTE, A. C. A Geografia Física no Brasil: um panorama quantitativo a partir de periódicos nacionais (1928-2006). Revista da ANPEGE, n. 4, p. 39-49, 2008.

Recebido em: 14/08/2016

Aceito para publicação em: 10/01/2016 